\title{
GEOESTRATEGIA, FUEROS Y MILICIA EN ARAGÓN, 1563-1645
}

\author{
Enrique Solano Camón \\ Universidad de Zaragoza
}

RESumen. En el contexto de las relaciones políticas e institucionales entre la corona y el reino de Aragón entre 1563 y 1645, se analizan en este estudio las tentativas, por parte de la monarquía, de involucrar al territorio aragonés en la necesaria renovación que su aparato militar precisaba, con objeto de atender a la defensa del noreste peninsular y de responder a la presión militar derivada de los objetivos políticos que esta perseguía en Europa. Al llegar a las cortes de Zaragoza de 1645-1646 las características del servicio de armas en Aragón apenas se habían transformado, pero su incorporación al aparato de defensa de la monarquía parecía un hecho.

Palabras clave: Aragón, fueros, cortes, milicias, Austrias españoles

Abstract. This paper is focused in the context of the political and institutional relations between the Crown and the Kingdom of Aragon between 1563 and 1645. This study analyzes the attempts by the monarchy to involve the Aragonese kingdom in the necessary reform of its military apparatus required in order to attend to the defense of the peninsular northeast. The monarchy wanted that the Aragonese could respond to the military pressure derived from the political objectives that Philip IV of Spain was pursuing in Europe too. When arriving at the Cortes of Saragossa in 1645-1646, the characteristics of the arms service in Aragon had hardly changed, but its inclusion into the defense organization of the monarchy was a reality.

Keywords: Aragón, fueros, cortes, militias, Spanish Habsburg

Recibido: 21-12-2020.Aceptado: 28-4-2021.esolano@unizar.es 
Al Llegar al trono Felipe II, frente al potencial militar con el que la monarquía contaba fuera del territorio peninsular apenas existía un ejército regular dentro de este, quedando su defensa encomendada primordialmente a las guarniciones de los castillos y fortalezas existentes, sobre todo en las cercanías de la costa y zonas fronterizas (Thompson, 1981, pp. 26-29). Realmente el sistema heredado del medievo era el que continuaba vigente en la defensa del interior de la península, al que desde 1493 se sumará la función singular de las guardas de Castilla, a la postre primera institución militar con carácter permanente en la mencionada Castilla (Martínez y Pi, 2012). Sin embargo, las limitaciones existentes en el propio sistema de reclutamiento, a las que ahora había que sumar las necesidades por las mismas contingencias bélicas, urgían la organización de la defensa peninsular de un modo más consistente.

Se trataba de dar forma a las tradicionales obligaciones militares de los municipios, hasta entonces dirigidas a su propia defensa, dotándolas de algún tipo de organización permanente. Con posterioridad a la etapa de los Reyes Católicos, periodo durante el cual se produjeron los primeros intentos en Aragón, como lo pone de manifiesto, a pesar de su corta existencia, la creación de la Hermandad en $1487^{1}$, el reinado de Carlos I también iba a contemplar diferentes proyectos encaminados a su constitución, sin que se alcanzasen los resultados pretendidos. De tal manera que al llegar a mediados del siglo XVI no podemos considerar la organización de milicias como representativa, una circunstancia que, además, hay que interpretar y valorar en el marco de las relaciones mantenidas entre la monarquía y los distintos reinos y territorios que la integraban, lo que, unido a la complejidad jurisdiccional que de ello se derivaba, condicionará los intentos de configurar un aparato de guerra capaz de responder a las exigencias derivadas de los objetivos políticos y militares por la corona perseguidos, en el ámbito internacional de un mundo en guerra (Thompson, 1981, p. 14).

$\mathrm{Y}$ es en ese contexto donde cabe situar al reino de Aragón, un territorio en el que continuaban sustancialmente vigentes las «formas antiguas del deber militar» heredadas del medievo y en el que la respuesta a los diferentes servicios de armas, requeridos por la corona, estaba supeditada al ordenamiento foral y a las condiciones que de él se derivaban, tales como la consideración voluntaria del servicio ofrecido, la naturaleza aragonesa de sus componentes, la defensa del propio territorio, la específica normativa prevista para cada contribución militar o las cláusulas y requisitos establecidos en las diferentes resoluciones acordadas por los municipios, la diputación del reino o las cortes (Solano, 2004, pp. 101-142).

$1 \quad$ El 18 de diciembre de 1487 se aprobaban los capítulos bajo los cuales esta institución debía regirse. La definían como una organización judicial y de policía. Sin embargo, la Hermandad quedaba en suspenso en las cortes de Tarazona de 1495 por la presión ejercida por la nobleza, mientras que en las cortes de Monzón de 1510 era definitivamente suprimida. Véase al respecto, Muñoz (1927). 


\section{Aragón en los primeros intentos de reorganización militar de la monarquía}

Durante el siglo XVI las peticiones de servicios de armas efectuadas a los aragoneses por parte de la corona, fueron respondidas por estos bien mediante servicios levantados por la diputación del reino, la nobleza o los municipios, bien mediante los llamados Servicios ordinarios votados en las cortes fernandinas, realizadas en Tarazona (1495), Zaragoza (1502) y Monzón 1512, en las que estos se ofrecieron (Solano y Sanz, 1998, pp. 249-254). En las restantes convocatorias a cortes llevadas a cabo durante el resto de la centuria, los servicios acordados serían de índole exclusivamente económica ${ }^{2}$. En cualquier caso, las solicitudes de servicios de armas habrían de intensificarse durante el reinado de Felipe II, ante la imperiosa necesidad de reorganizar el dispositivo de defensa en la península (Thompson, 1981, pp. 26-28, 45-49, 364-369).

Así se hacía patente el 8 de julio de 1558 cuando la ciudad de Zaragoza expresaba su intención de contribuir con 10.000 escudos y socorrer a la ciudad de Barcelona, frente al turco, con 500 infantes en dos compañías de 250 hombres cada una y 50 hombres a caballo, pagados durante dos meses ${ }^{3}$. Y pocos días después cuando, habiendo tenido noticia de que los turcos habían tomado la ciudadela de Menorca y de que estos, coaligados con los franceses, pretendían atacar la plaza de Perpiñán, el rey encomendaba a don Juan de Gurrea, gobernador de Aragón, que movilizase en el reino un contingente de 1.000 hombres de armas ${ }^{4}$.

Sabemos que a mediados de agosto la gente ofrecida por los municipios aragoneses para el socorro de Cataluña era la siguiente: las ciudades de Huesca, Barbastro y Calatayud, así como las villas de Alcañiz y Ejea de los Caballeros, habían ofrecido 100 hombres cada una; la ciudad de Albarracín, 70 más; las ciudades de Daroca, Tarazona y Teruel, junto con las villas de Monzón y Caspe, 50 hombres cada una; la ciudad de Borja había ofrecido 40; las villas de Tauste, Uncastillo, Sos y Sádaba se habían comprometido con 100 hombres en total; la villa de Tamarite de Litera con 25 y la villa de Magallón con otros 12 hombres más. Lo que representaba 997 hombres de armas, sin contar con los de las comunidades de Calatayud, Daroca y Teruel, que de ser movilizados alcanzarían, en conjunto, otros 600 hombres de armas más. Pocos días más tarde, el 20 de agosto, el gobernador enviaba una misiva a Felipe II infor-

2 Su cuantía económica, 200.000 libras jaquesas, había sido establecida en las cortes de Monzón de 1510. Solo en las cortes de Monzón de 1585 se duplicaría esta cantidad, como también ocurrió en los restantes territorios peninsulares de la antigua corona de Aragón, mientras que en las cortes de Tarazona de 1592 se incrementaba a 500.000 libras jaquesas en respuesta a las alteraciones recientemente producidas en el reino.

3 Archivo Municipal Zaragoza (en adelante AMZ), Serie facticia, caja 5, núms. 51-52-53.

4 Biblioteca Nacional España (en adelante BNE) Sección manuscritos, ms. 784, f. 17. 
mándole de que en Aragón se habían movilizado hasta 1.700 hombres, «de los que les llegaron allá algunos y lo huvieran hecho todos, pues los que querían y podían por estar ya apunto dexaron de hazello por falta de necesidad ${ }^{5}$. Más allá de su efectividad, esta movilización convertía a los municipios aragoneses en el principal referente sobre el que en lo sucesivo iba a pivotar cualquier intento de estructurar las milicias del reino al servicio de la monarquía (Solano, 1996, pp. 270-271).

En este sentido, un ejemplo característico de movilización municipal lo vamos a encontrar en Zaragoza en 1570, cuando los jurados de la ciudad pedían a los distintos capítulos parroquiales que hiciesen investigación del número de personas, que formaban parte de cada una de dichas parroquias, así como de las armas de las que se disponía, con el fin de que estuviesen prevenidas en caso de necesidad, a causa «de esta guerra que los moros an movido cuentra nuestro señor, como contra los luteranos y enemigos de nuestra sancta fe católica, que an intemptado de entrar en estos Reynos». Una vez nombradas las personas encargadas de hacer la investigación, esta debía realizarse por casas representadas por el cabeza de familia. Cada una de las calles quedaría subdividida en grupos de diez casas. Realizado el censo, este quedaría distribuido en grupos de 100, 50 y 10 hombres, gobernados respectivamente por los centeneros, cinquenteneros y deceneros. No se conoce cuál fue el resultado de estas prevenciones, sin embargo, consta que el concejo de la ciudad gastó este año la cantidad de 55.000 sueldos jaqueses en la compra de picas, morriones y arcabuces, con objeto de adiestrar a la gente en su uso (Jarque, 1982, p. 269). Otros municipios del reino también habían utilizado mecanismos parecidos, como el de Jaca en $1559^{6}$ o el Barbastro en $1566^{7}$.

Ciertamente, durante el reinado de Felipe II la administración de guerra de la monarquía pretendió una gestión directa, con el fin de fortalecer el control sobre el aparato militar. Algo que se mantendría hasta el umbral de los años ochenta, cuando la situación financiera obligó a volver a procedimientos indirectos, como ya había ocurrido en tiempos de su padre y antecesor, el emperador Carlos, aunque, sin duda, la coyuntura era ahora diferente (Solano, 1996, p. 276).

Por entonces, ante la creciente necesidad de adecuar la capacidad militar de la monarquía al mundo en guerra en el que esta se debatía, el «sistema de comisión o reclutamiento administrativo», mediante el que el consejo de Guerra promovía la movilización y recluta de hombres de armas, venía siendo el más habitual. Lo era en la corona de Castilla, al menos hasta 1580, mientras que en otros reinos como Navarra, Valencia y Aragón, tendría un ejercicio más limitado en consonancia con

BNE, Sección manuscritos, f. 35.

Archivo Municipal Jaca (en adelante AMJ), Actas, leg. 3, acuerdo de fecha 5 de julio de 1559.

Archivo Municipal Barbastro (en adelante AMB), Actas, leg. 204, acuerdo de fecha 8 de marzo de 1566. 
el menor número de hombres de armas en ellos movilizado. Algo diferente ocurría en otros territorios donde los soldados reclutados se obtenían mediante la práctica de otros métodos, destacando entre ellos el «reclutamiento intermediario» realizado por agentes que ofrecían su influencia local a la corona a cambio de una gracia regia. Tal es el caso de Asturias, Galicia, las provincias vascas o Cataluña. Una circunstancia, que no impidió que la monarquía contemplase la posibilidad de incluir también a los aragoneses en la creación de una milicia general, capaz de precaver con mayor eficacia la defensa del territorio peninsular, siempre que ello fuera preciso (Solano, 1996, pp. 278-279).

Efectivamente, la situación de conflictividad planteada en Francia a partir de 1562, unida a las amenazas en el Mediterráneo, pronto agravadas por la rebelión de las Alpujarras acaecida en 1568, impedían cualquier demora en la actualización del inadecuado sistema defensivo peninsular. La corona tratará de dotar de una organización más permanente a las tradicionales obligaciones militares de los municipios, hasta entonces dirigidas a precaver su propia defensa, así como de incentivar reformas dirigidas a implementar los recursos, tanto en lo que atañe a la misma estructura militar como en lo relativo a las fortificaciones y arsenales existentes (Thompson, 1981, pp. 28-36).

Las ordenanzas promulgadas por Felipe II en Castilla en 1562 no habían obtenido los resultados apetecidos. La conmoción ocasionada por la rebelión granadina, sin embargo, estimulaba la emisión de distintos informes y memoriales encaminados al análisis y valoración de la estructura defensiva del territorio. Entre otros, el informe que, con el título «Razones por las cuales el reino de Aragón debe contribuir como los demás reinos a la defensa de España», redactó Juan López de Velasco para presentarlo al monarca en 1571 (Sánchez, 1997, pp. 479-483). Con fecha de 10 de noviembre de 1577 y respondiendo al real mandamiento hecho por Felipe II, se trasladaba a la corte otro informe dando cuenta del estado en el que se encontraba la investigación, que se estaba realizando en Aragón, dirigida a la creación de una milicia al servicio del rey, gobernada por el virrey, don Artal de Alagón, conde de Sástago ${ }^{8}$.

El proyecto de movilización era muy ambicioso a tenor de las cifras que ofrecía. Contemplaba distintos cuarteles o zonas de reclutamiento distribuidas por todo el territorio a las órdenes de un capitán. Los cuarteles que en el informe se establecían eran los siguientes: cuartel de Tarazona y Borja; cuartel de Alcañiz; cuartel de Calatrava y Santiago; cuartel de Barbastro; cuartel de Jaca y sus montañas; cuartel de Cinco Villas; cuartel de Huesca y su Partido; cuartel de Daroca y su comunidad; cuartel de Calatayud y su comunidad; y cuartel de Cantavieja (Sánchez, 1993, pp. 51-52).

8 BNE, Sección manuscritos, ms. 729, ff. 1-6, «Lista de gentes y armas que hasta el presente día de hoy a 10 de noviembre de 1677 han dado las universidades». 
No deja de ser sintomático que la ciudad de Zaragoza no aparezca en la relación de cuarteles o zonas de reclutamiento, que figuran en el informe ${ }^{9}$. Una circunstancia que, no obstante, parece aclararse en la exposición inicial del mismo, donde se lee que en la confección de la relación de hombres y armas, que hasta entonces se habían hallado en el reino, algunos municipios se resistían a presentar las listas «por renitencia del no hazello las ciudades de Caragoça y Huesca» ${ }^{10}$.

Al final, el proyecto no llegó a consumarse, pero, sin duda, puso en evidencia el interés de la corona por estructurar bajo su control un dispositivo militar y de defensa en un territorio, como el aragonés, que en estos momentos poseía un indudable valor estratégico para la monarquía. Un territorio que, además, estaba dando por entonces muestras de inseguridad debido a la conflictividad social y política existente, acompañada del incremento de la actividad del bandolerismo, motivo de creciente preocupación para la corona. De hecho, la intensificación del fenómeno del bandolerismo durante la década de los sesenta obligó al reino aragonés a intervenir en su represión, alarmado por la amenaza que representaba para su actividad mercantil y, en consecuencia, para las Generalidades, principal fuente de ingresos de su hacienda.

En el verano de 1563, en una atmósfera enrarecida a causa de la falta de respuesta de la corona ante lo que las instituciones del reino consideraban transgresiones forales, se inauguraban nuevas cortes en Monzón. Entre otras medidas dirigidas a hacer frente a la inestabilidad del orden público, se acordaba el fuero «De la facultad que tienen los diputados para poder gastar de la Generalidades del Reino», que situaba en 2.300 libras jaquesas la cantidad que podían usar los diputados «en defensa de las libertades o en otras materias del Reino» (Savall y Penén, 1866, p. 401). Una iniciativa todavía insuficiente, pero que lo dotaba de un presupuesto con el que hacer frente a los problemas de inseguridad, sin que eso representase coste alguno para el erario real.

Sólo unos años después, en 1569, la diputación del reino destinaba la suma de 5.000 libras jaquesas para hacer frente al bandolerismo; una cantidad que poco más tarde ascendería a 14.000 (Colás y Salas, 1982, p. 327). Resultado de ello era la creación de la Guarda ordinaria del reino, cuyo origen establecen Gregorio Colás y José A. Salas en 1568, alcanzando una conformación más definitiva en 1572, tras la movilización efectuada por la diputación del reino para reprimir el bandolerismo.

Con este contingente armado, única estructura militar de carácter permanente en Aragón, la diputación del reino pretendió garantizar la seguridad en los caminos y, en general, la persecución de delincuentes y bandoleros. Pero junto a ello, ocasionalmente, también realizó otras funciones como dispensar apoyo al gobernador, escoltar a los emisarios reales, demás autoridades, objetos y mercancías valiosas, o dar pro-

9 Para comprender el papel desempeñado por la ciudad de Zaragoza a lo largo del estudio, se recomienda la consulta de la obra de Jarque (2007, pp. 1-428). 
tección a los convoyes de moneda que transitaban por tierras del reino. Los presidios de la Guarda se encontraban en los lugares considerados como más adecuados para garantizar la seguridad de los viajeros y desde ellos las distintas escuadras, a pie o a caballo, reconocían los espacios de su competencia. También se crearon guarniciones eventuales en función de las circunstancias e, incluso, con carácter excepcional como los puestos de Ariza y Calatayud, cuando pasó Felipe II por Aragón para asistir a las cortes de Monzón de 1585 (Colás y Salas, 1982, pp. 350-354).

Durante 1572 el ostensible incremento de la actividad del bandolerismo, unido a los recursos de los que se había dotado el reino, animó a la diputación a organizar una operación militar sobre aquellas zonas de Aragón más castigadas por el problema, recurriendo para ello a la colaboración de los municipios, primordialmente de aquellos más castigados por este, pidiéndoles gente diestra en el uso de las armas y dispuesta si la situación así lo requería.

El contingente se estructuró en 60 jinetes distribuidos en tres escuadras de 20 cada una y 200 arcabuceros organizados en escuadras de infantes, gobernadas cada una por un cabo. El contingente se completaba con un trompeta, un herrero y un intendente, todos ellos ocupando una plaza de a caballo; un acemilero, encargado de transportar la munición; un aposentador, encargado de alojar a la tropa en las localidades; un notario con su correspondiente secretario; y el pagador de la gente, al que competía realizar la muestra y la entrega del salario a los soldados. La gente percibiría de la diputación el salario una vez que se hubiese integrado en el contingente. Un salario cuyo montante durante un mes ascendió a la cantidad de 1.790 libras jaquesas. Al finalizar la campaña realizada durante el verano, la Guarda volvió a sus actividades cotidianas adquiriendo una estructura más definitiva (Colás y Salas, 1982, pp. 329-340).

\section{La rebelión de 1591 y la incorporación de Aragón en el aparato de defensa de la monarquía}

A lo largo de la década de los setenta los aragoneses, ante la situación de deterioro por la que atravesaba el reino, reclamaron sin éxito la convocatoria de cortes, quedando frustrada la pretensión de celebrarlas en $1578^{11}$. En 1583 la diputación del reino se lamentaba del tiempo que había transcurrido sin que el monarca hubiese visitado a los aragoneses ${ }^{12}$, precisamente en unos momentos en los que se presagiaba en el escenario internacional una intensificación de la conflictividad como consecuencia de la participación directa de España en los asuntos de Francia.

\footnotetext{
11 Archivo Corona Aragón, (en lo sucesivo ACA), Consejo de Aragón (en lo sucesivo CA), Secretaría de Aragón, leg. 1351, doc. 1.

12 Archivo Diputación Zaragoza (en lo sucesivo ADZ), Actos comunes, ms. 245, f. 35.
} 
Efectivamente, con la firma del Tratado de Joinville entre el monarca español y la casa de Guisa, el 31 de diciembre de 1584, se acordaba la formación de una Liga Santa con la pretensión de acabar con la herejía en Francia y los Países Bajos. Tal hecho implicaba a la Monarquía Hispánica en una larga y costosa escalada bélica. Así estaban las cosas cuando el 28 de junio de 1585, por fin, se abrían cortes en la villa de Monzón. En ellas se concedía un elevado servicio económico, que representaba 400.000 libras jaquesas, el doble de lo habitual. Un incremento que hay que interpretar en el escenario de la política internacional de la monarquía y del cuantioso presupuesto de defensa que ello estaba suponiendo ${ }^{13}$. En estas cortes se trataban asuntos que afectaban de forma importante a la vida del reino. Sin embargo, tras su conclusión, lejos de verse mejorada su situación, este iba a introducirse en una espiral de importante inestabilidad (Colás y Salas, 1982, pp. 595-631).

Así las cosas, don Alonso Celdrán era nombrado ayudante del anciano gobernador de Aragón, don Juan de Gurrea, en el verano de 1587. Un significativo paso que la corona daba en Aragón para así luchar con mayor efectividad contra el bandolerismo y los peligros que en él veía para la estabilidad del territorio. Pocos meses después la diputación del reino resolvía movilizar, tal y como ya lo había hecho en 1572, un ejército para hacer frente a la alarmante actividad de «gentes extranjeras y naturales de mala vida que por él andan en cuadrillas y desmandados», por lo que en la primavera de 1588 solicitaba licencia al rey ${ }^{14}$.

El nuevo contingente, al mando de don Juan de Lanuza «el Viejo», Justicia de Aragón, debía quedar conformado por 120 jinetes distribuidos en cuatro escuadras, a razón de 30 hombres cada una, con su respectivo capitán encargado de elegir un teniente y escoger personalmente los jinetes de sus respectivas escuadras; así como de 1.000 infantes, organizados en cuatro unidades de 250 hombres gobernadas por sus respectivos capitanes, a los que se les había asignado, respectivamente, como zona de reclutamiento de la gente de guerra, las Cinco Villas, Daroca y su comunidad, Calatayud y su comunidad, así como las comarcas de Tarazona y Borja. Cada una de estas unidades incluiría, además, un sargento y diez cabos, también elegidos por sus capitanes, que dispondrían de 15 mosqueteros en calidad de guardia personal permanente Para todos los conceptos tocantes al mantenimiento de la tropa los diputados habían previsto un montante total de 10.000 libras jaquesas. Las expectativas puestas en el contingente armado, derivaron no obstante en el fracaso experimentado en la acción emprendida por este «pequeño ejército» en tierras de Ribagorza (Colás y Salas, 1982, pp. 396-401).

13 Si antes del año 1566 el gasto militar realizado por Castilla no había superado los 2.000.000 millones, en torno a 1590 dicha cantidad prácticamente se había quintuplicado, pudiéndose calcular en 10.000.000 millones de ducados (Ulloa, 1963, pp. 501-540). 
Los escasos frutos cosechados por la milicia aragonesa, tanto en el proceso de movilización como en los objetivos perseguidos, puestos en evidencia en tierras de Ribagorza, movían a las autoridades reales a promover la movilización de otro contingente armado, siguiendo un procedimiento parecido al orquestado por el reino, pero en esta ocasión a costa del erario real, mientras estudiaban la posibilidad de introducir tropas desde Castilla en territorio aragonés ${ }^{15}$. Todo ello en el contexto de un escenario agitado, en el que la política se expresaba a través de dos sensibilidades bien distintas: la representada por el rey y su autoridad y la encarnada por el reino y sus prerrogativas forales (Gascón, 2007, vol. II, pp. 53-127).

El municipio zaragozano, por su parte, con el acuerdo de Huesca y Barbastro, impulsaba en el verano de este mismo año «un desafuero y unión universal con todas las ciudades y villas» con intención de extenderlo al conjunto del territorio aragonés ${ }^{16}$. Una iniciativa que no acabó prosperando debido a la falta de entendimiento producida a última hora entre el zaragozano Privilegio de los Veinte, apoyado por el rey, y la diputación del reino, a causa de asuntos jurisdiccionales en los que también intervino el Justicia de Aragón ${ }^{17}$, quedando su resolución diferida a un acuerdo en cortes $^{18}$. Mientras tanto, los diputados aragoneses habían pedido a Felipe II que les permitiese ampliar la capacidad de acción de la Guarda. Algo que aceptaba el rey, pero siempre que el nombramiento de los oficiales de la nueva tropa, que se proponía, fuera de competencia real, pues de no ser así «era cosa perjudicial y inútil, como también lo es la guarda» ${ }^{19}$. La falta de acuerdo hizo, finalmente, que la diputación del reino desistiese del proyecto.

El 12 de noviembre de 1591 la tensión acumulada entre Aragón y la corona provocaba la entrada en Zaragoza del ejército real al mando de don Alonso de Vargas (Gracia, 1992). Con ello se ponía fin a la rebelión aragonesa, mientras que las detenciones del conde Aranda, el duque de Villahermosa y el Justicia de Aragón, don Juan de Lanuza «el Mozo», acompañadas de la inmediata ejecución de este último el 20 de diciembre y la de los dos restantes más tarde, daban paso a una dura represión. Meses después, el 15 de julio de 1592, se inauguraban cortes en Tarazona (Jarque, 1991, pp. 105-119; Gascón, 2010, pp. 283-419).

En ellas se adoptaban importantes acuerdos que afectaban directamente a cualquier tipo de prevención armada que pudiera promoverse en el reino (Savall y Penen, 1866, pp. 425-445). Tal es el caso del fuero: "Que la gente de la guarda ordinaria del Reyno esté a disposición del que presidiere la Real Audiencia», que consumaba la

15 Biblioteca Real Academia Historia (en lo sucesivo BRAH), Col. Salazar y Castro, ms. K-41, f. 60.

16 AMZ, Serie facticia, caja 130, nº 6 .

17 BNE, Sección manuscritos, ms. 8680, cartas 24 y 27.

18 BNE, Sección manuscritos, ms. 7.377, ff. 35-6, (véase una síntesis de las mismas en Sánchez, 1993, pp. 52-54). 
intención de la corona de poner la Guarda bajo su control, quedando a disposición del virrey, a quien competía presidir la Real Audiencia, solo en su ausencia sustituido por el gobernador (Lalinde, 1963, pp. 188-200). Respecto a la movilización de milicias en el reino otro fuero, «Que todos los Diputados del Reyno no puedan hazer convocaciones», imposibilitaba al mismo para realizar cualquier tipo de movilización armada, que no contase con el beneplácito de la corona. A estos había que sumar el fuero «De la facultad de gastar los diputados por consulta», que permitía a los diputados realizar consultas cada año ante la corte del Justicia de Aragón «hasta la suma de cinco mil libras, ultra y á más de las dichas tres mil», con el fin de dar respuesta a los problemas de inseguridad en el reino, consolidándose con ello la vía de actuación ya iniciada en las cortes de Monzón de 1563. Tres fueros que, junto con otros, quedaban convertidos en herramientas sujetas a la normativa foral, que posibilitan el control de la corona sobre la endeble capacidad defensiva de Aragón y, por ende, su papel en el aparato militar de esta. Este es el caso del fuero «Del Officio del Justicia de Aragón», cuyo cese quedaba en lo sucesivo sujeto a disposición del soberano ${ }^{20}$, o del titulado «Del virrey Extranjero», que sobreseía el pleito hasta nueva convocatoria de cortes, teniendo el rey la libre elección del cargo sin atenerse a su posible condición foránea (González, 1986, pp. 251-268).

Por otra parte, los recientes sucesos acaecidos en Aragón, los temores de contagio hugonote, así como los frentes abiertos en el escenario bélico internacional propiciaban que Felipe II ordenase la creación de un dispositivo de torres y fortalezas para prevenir la defensa del Pirineo ante cualquier incursión desde la vecina Francia. Un dispositivo que hurtaba al reino toda iniciativa de control e intervención. La frustrada invasión del valle de Tena desde el Bearne francés en 1592 había sido el detonante (Gómez, 1992, pp. 5-64; Sanz, 1992, t. 1, pp. 143-156; Gascón, 2004, pp. 471-496). Este mismo año, Tiburcio Spanoqui, colaborador de don Alonso de Vargas y responsable de la planificación y fortificación del dispositivo de defensa, remitía a Felipe II una pormenorizada descripción de las características geográficas y defensivas del Pirineo ${ }^{21}$. Dicha información, unida a la «Instrucción para las cosas tocantes a la guerra y otros de los castillos del Reino», remitida el 26 de abril de 1594 por Felipe II al virrey de Aragón, el duque de Alburquerque, no hacía otra cosa que sancionar los propósitos de la corona en relación con el territorio aragonés ${ }^{22}$. Pretendía la instrucción, en primer lugar, mantener la quietud de los naturales del reino, lo que se expresaba en los siguientes términos:

20 Para una mejor interpretación de la función institucional del Justicia de Aragón con respecto a los proyectos y actuaciones que la monarquía pretendió introducir en Aragón nos remitimos, entre otros, a Salas y Jarque (2003, pp. 155-172).

21 Archivo General de Simancas (en lo sucesivo AGS), Guerra Antigua, leg. 351, doc. 242, (véase también Osset, 1992, pp. 213-228). ACA, CA, Secretaría de Aragón, leg.67, (véase también Camón, 1959, pp. 118-124). 
considerando la alteración que en la Ciudad de Zaragoza causaron algunos sediciosos y el gran desacato que cometieron contra el Santo Oficio de la Inquisición los días 24 de mayo y septiembre respectivamente del año 1591 y la entrada que los herejes Viarneses hicieron el año siguiente de noventa y dos en las montañas de Jaca a instancia de los dichos sediciosos y el peligro que aquella ciudad corriera de ser ocupada, si no fuera por el ejército que en aquella sazón se halló en el Reyno, y lo que convenía al servicio de Dios y mío seguridad, quietud y reposo de los naturales dél escusar en lo venidero semejantes peligros e inconvenientes.

A continuación, disponía la organización del dispositivo de defensa del siguiente modo: en la ciudad de Zaragoza debía repararse y pertrecharse la Aljafería y construirse junto a la ciudad de Jaca una ciudadela, así como otro fuerte en Berdún. En el Pirineo se tenían que construir las torres de Santa Elena, Hecho, Ansó, Espelunca y Baños, así como repararse los castillos de Canfranc, Benasque y la ciudadela de Aínsa, a lo que había que sumar, además, la reparación del castillo de Castellón, en el valle de Arán, con el fin de establecer una línea de contención frente a posibles ataques desde Francia. Para su custodia y guarnición se consideraba también la formación de un contingente de 1.000 hombres, distribuidos del siguiente modo: 200 infantes en la Aljafería; 400 en el castillo de Jaca, plaza que quedaba convertida en cabecera principal del Pirineo; 100 infantes en el castillo de Berdún; 80 en el de Benasque; 130 más en la ciudadela de Aínsa; y en el castillo de Castellón otros 40 infantes. Plazas todas ellas que estarían gobernadas por sus correspondientes capitanes. Por otro lado, cada una de las cinco torres de vigilancia de los pasos pirenaicos sería guarnecida por 10 hombres, bajo el mando de su correspondiente sargento mayor y subordinada al castillo que más cerca tuviese, dependiendo este, a su vez, de quien gobernase en el castillo de Jaca. La máxima autoridad del contingente armado la ostentaría el virrey de Aragón.

Igualmente contemplaba la instrucción real otras cuestiones inherentes al servicio del contingente armado, como las relativas a su salario, abastecimiento, forma de relacionarse con las gentes o con la actividad comercial del reino, así como las medidas disciplinarias que, en su caso, se tuviesen que aplicar. Finalmente, hacía mención expresa de que entre la gente movilizada para la formación de este contingente no se admitiesen naturales del reino, por los inconvenientes que de ello se podían derivar.

La creación del sistema defensivo del Pirineo, establecido por Felipe II, iba a intensificar los conflictos de jurisdicción entre la corona y el reino de Aragón, derivados de la diferente interpretación en la aplicación del fuero del «Capitán de guerra», acordado en las cortes de Monzón de 1528 para dar respuesta a los conflictos jurisdiccionales en el Pirineo (Solano, 1997, pp. 485-495). Unos conflictos afectados por la propia naturaleza del virrey y el pleito que ello suscitó e intensificados, también, 
por el nuevo papel estratégico que había adquirido el reino en Europa, como consecuencia del establecimiento de la casa de Austria en España ${ }^{23}$.

El fuero quedaba redactado en los siguientes términos:

Los juezes ordinarios son impedidos en el ejercicio de su jurisdicción, y los regnícolas deste Reyno perjudicados por el Capitán de guerra, queriéndose entrometer en tiempo, casos, y cosas, que no son de guerra lo qual por Fuero hazer no pueden. Por ende su Majestad, de voluntad de la dicha Corte estatuye, y ordena, que el dicho Capitán de guerra no se pueda entrometer, conocer, ni exercir jurisdicción, sino en tiempo y personas de la guerra, y cosas concernientes a la guerra tan solamente, y no en otras, y casos, como ya por fuero esta estatuydo.

A esta conflictividad jurisdiccional se sumaban, además, otros inconvenientes como los provocados por el cierre de los pasos del Pirineo, justificados en la filosofía pretendida por la corona con la aplicación del fuero de «Capitán de guerra». Circunstancias todas ellas que en diferentes ocasiones indujeron a los diputados a elevar consultas ante la corte del Justicia de Aragón, cuya doctrina se encuentra dictada en diferentes jurisfirmas recogidas en el siglo xvi por distintos tratadistas y jurisconsultos, como el zaragozano Juan de Bardaxi, quien en sus Comentarii sobre los fueros manifestaba expresamente la necesidad del concurso copulado de tiempo, personas, cosas y casos de guerra, «y que de otra suerte no se puede platicar el ejercicio de la jurisdicción del Capitán de Guerra» (Bardaxi, 1597). Un criterio este, que el reino sostenía frente a la versión defendida por la corona, que no consideraba preciso el concurso copulado de tiempo, personas, cosas y casos de guerra. Lo que parece claro, en cualquier caso, es que con el fuero acordado en las cortes celebradas en 1528 la monarquía se encontró con un instrumento de carácter jurisdiccional, dirigido a la nueva función estratégica que Aragón iba a desempeñar, aunque su alcance e interpretación mantuvieran vigente el pleito sobre la aplicación de la jurisdicción del «Capitán de guerra» hasta finales del siglo XVII (Solano, 1996, pp. 487-495).

23 En esta cuestión cabe considerar la relación formulada por los aragoneses entre la jurisdicción del «Capitán de guerra» y el que hiciese uso de ella, teniendo en cuenta que en su origen esta iba unida a la del lugarteniente general y virrey, y este, hasta la promulgación del fuero del «Virrey Extranjero» acordado en las cortes de Tarazona de 1592, requería foralmente la naturaleza aragonesa. Una condición que posteriormente a estas cortes volvería a ser reclamada, aunque sin éxito, por los aragoneses. 


\section{Aragón en el plan de Olivares ante la nueva coyuntura internacional}

Todavía recientes las Ordenanzas Generales publicadas en Castilla en 1590, los acuerdos de Tarazona de 1592 y el sistema defensivo ordenado para el Pirineo por Felipe II, como acabamos de ver, habían puesto de manifiesto la función que el territorio aragonés debía tener en el aparato defensivo y militar de la Monarquía Hispánica. Una muestra de ello la encontramos en las Juntas que se van a celebrar en la ciudad de Zaragoza en 1601. Convocados los estamentos del reino el día 10 de junio en la Sala Real de la diputación del reino, el virrey de Aragón, duque de Alburquerque, exponía la resolución de Felipe III sobre aprestos de guerra, comunicándoles su intención de:

tener en esse Reyno desde luego armados y aprestados hasta ocho o diez mil hombres de guerra con los cabos y capitanes y otros offiçiales que para ello son menester, de manera que estén tan en orden que no solamente puedan resistir y defenderle a todos los que quisieren invadirle sino también, si conviniere, acudan a las fronteras y entren en tierra de enemigos para ofenderles y devilitarles las fuerzas. Y haviendo considerado de quan grande pesadumbre y molestia sería para los de esse Reyno imbiar a él esta gente de otra parte y el sentimiento que dello podrían tener $[\ldots]$ me he resuelto de valerme de la de él pidiéndola al Reyno por medio de los Dipputados ${ }^{24}$.

Para la movilización de esta fuerza armada, una vez hecha la solicitud, se concedían dos meses. El mando de la misma correspondía al virrey quien, de consuno con las personas propuestas por los estamentos, nombraría a los capitanes, oficiales y demás gente precisa para el gobierno de la leva, debiendo ser todos ellos naturales del reino.

La movilización no llegó a producirse a causa de los obstáculos de carácter foral, surgidos en el debate llevado a cabo por los estamentos en el seno de las Juntas durante buena parte del verano ${ }^{25}$. Sin embargo, los términos en los que estaba formulada la solicitud regia no solo evidencian los propósitos de la administración de guerra de la monarquía para estructurar un sistema de milicias en Aragón ${ }^{26}$, sino que ya anuncian en buena medida la filosofía política y los criterios organizativos

24 BNE, Sección manuscritos, ms. 729, ff. 310-311.

25 BNE, Sección manuscritos, ms. 729, ff. 335-336, «Voto del braço de caballeros e hijosdalgo», donde queda reflejada la respuesta del reino.

26 Conviene recordar que Juan López de Velasco, sucesor de Alonso de Santa Cruz en 1572 como cronista de Indias, este mismo año, en su informe remitido al monarca con el título «Razones por las cuales el reyno de Aragón debe contribuir como los demás reinos a la defensa de España», anticipaba de algún modo el proyecto de «Unión de Armas» impulsado décadas después por el Conde-Duque de Olivares (Sánchez, 1996, pp. 479-483). 
que el Conde-Duque de Olivares impulsaría apenas veinticuatro años después en su proyecto político, cuya expresión formal se encontrará en el «Gran Memorial» o memorial secreto presentado a Felipe IV, con fecha de 25 de diciembre de 1624, y más concretamente en el documento conocido como «Unión de Armas» (Rivero, 2017, pp. 121-147).

La respuesta al plan militar de Olivares tenía su respuesta en las cortes convocadas en Barbastro para 1626. Las cortes comenzaban el día 21 de enero con la lectura de la «Proposición» en presencia del rey Felipe IV, trasladándose posteriormente a Calatayud en donde el 18 de abril continuaron bajo la presidencia del conde de Monterrey, concluyendo el 21 de julio de este mismo año. Inicialmente, el servicio solicitado había sido de 3.333 hombres disponibles para la guerra y de 10.000 hombres más en situación de reservistas, por si era precisa su movilización. Estos reservistas quedarían supeditados a las siguientes condiciones: no tendrían paga; estarían exentos de la jurisdicción militar hasta que las necesidades bélicas requiriesen su movilización; la oficialidad sería natural del reino; los propios aragoneses serían los encargados de recaudar lo necesario para soportar su mantenimiento y solo en caso de que en Aragón no se alcanzara el número suficiente de voluntarios, estos se buscarían en otros reinos ${ }^{27}$.

Si el territorio aragonés fuese atacado sería defendido por sus reservistas, añadiéndose a ellos la séptima parte de la reserva que estipulaba el proyecto de «Unión de Armas», es decir 20.000 hombres del total de los 140.000 que figuraban en el mismo, más 4.000 caballeros. Si la guerra tuviese lugar en otro reino de la monarquía, entonces sería Aragón el que aprestase una séptima parte de sus reservistas (1.400 hombres de armas); si en dos reinos, acudiría con dos séptimas partes (2.800 hombres de armas), y así sucesivamente ${ }^{28}$.

Sin embargo, finalmente, en las cortes de Barbastro-Calatayud se acordó un servicio económico de 144.000 libras jaquesas anuales, equivalente al mantenimiento anual de 2.000 hombres de armas, por un periodo de 15 años, iniciando su pago en 1628 (Colás y Salas, 1975, pp. 87-139; Solano, 1987, pp. 39-60).

Con la firma del Tratado de Monzón el 5 de mayo de 1626, la situación internacional parecía haber quedado estabilizada en el paso alpino de la Valtelina a favor de los intereses españoles. No obstante, poco tiempo después la intervención de Olivares en la guerra de Mantua (1628-1631) en apoyo del gobernador de Milán, don Gonzalo de Córdoba, y con intención de conquistar la plaza de Casale para asegurar la ruta entre Barcelona y Viena, no solo dejaba a la monarquía al borde de la guerra declarada con Francia, sino que presentaba nuevos y elevados gastos, que obligaban a la corona a considerar la convocatoria de nuevas cortes. Escribe Domínguez Ortiz,

27 ADZ, Actos de Cortes, ms. 373, f. 49.

28 ADZ, Actos de Cortes, ms. 373, f. 25v. 
«a partir del año 1632 la Monarquía Hispánica, temiendo ser atacada en cualquier momento, se planteaba si no debía de tomar la iniciativa» (Domínguez, 1960, p. 45).

Este debate se había convertido en habitual en las consultas de los consejos de Estado y Guerra, estudiándose alternativas de carácter militar con fines defensivos e incluso ofensivos, cuya repercusión en Aragón era inevitable. Era preciso ahora que se reunieran cortes en el principado catalán, tras las inconclusas celebradas en Barcelona en 1626 (Elliott, 1977, pp. 193-221). Aragoneses y valencianos también serían convocados para celebrar cortes en Teruel el 5 de julio, con objeto de solicitarles subsidios para hacer frente a los progresos que las armas del rey de Suecia estaban realizando en territorio imperial, en unos momentos en que el elevado montante ofrecido por las cortes castellanas se mostraba insuficiente para hacer frente a la situación ${ }^{29}$. Sin embargo, a pesar de las diferentes fechas de convocatoria que se fueron sucediendo, en el reino aragonés no se abrieron cortes ${ }^{30} \mathrm{y}$ tampoco las hubo en el de Valencia (Lario, 1986, pp. 281-283). En las convocadas en Cataluña, el monarca no obtenía los resultados pretendidos pues, inauguradas el 18 de mayo de 1632 quedaban paralizadas el 8 de junio siguiente como consecuencia de un dissentiment planteado por la ciudad de Barcelona. Y después, habiendo sido prorrogadas hasta el 24 de octubre, no llegaban a clausurarse (Elliott, 1977, pp. 246-255).

El 5 de agosto de 1634 Felipe IV solicitaba al reino aragonés, una vez más, que se juntasen sus estamentos. El día 20 del mismo mes don Fernando de Borja, virrey de Aragón, en la Sala Real de la diputación leía la «Propuesta» en nombre del monarca $^{31}$, donde expresaba la necesidad en la que se encontraban «las armas de su Magestad defendiendo la Fe Católica ${ }^{32}$. Por ello, aun reconociendo el esfuerzo que estaba suponiendo el servicio concedido por los aragoneses en las cortes de 1626, la insuficiencia de los muchos subsidios concedidos en Castilla y la concentración al otro lado del Pirineo de un elevado número de fuerzas enemigas, hacían preciso precaver la defensa de las fronteras del reino. Motivo por el que el monarca solicitaba que:

disponiéndose para en un año (que parece que es el tiempo que verisímilmente podrá durar el asiento destas cosas, pues de ver que se toma en todos mis Reynos, con el calor, y esfuerço que conviene, ha de resultar que tomen mejor disposición) se paguen hasta dos mil hombres corriendo por quenta del mismo Reyno la paga, pues mi ánimo no es que se convierta en otra cosa, que en ofensa contra Francia,

29 BNE, Sección manuscritos, ms. 6748, f. 1; AMZ, Serie facticia, caja 25, «Convocatoria de 5 de julio de $1632 »$.

30 ADZ, Actos comunes, ms. 394, ff. 167, 170-171, 175-176, 180-180v, 191-191v.

31 BNE, Sección manuscritos, ms. 6787 ff. 22v-29v, «Juan José Porter y Casanate. Anales del Reyno de Aragón, que contienen las guerras de Cataluña en el reynado del Rey Nuestro Señor Don Felipe III en esta Corona y IIII en la de Castilla», 1670. 
por ser esta su mayor defensa, y que ellos dispongan los medios que mejor pareciere $^{33}$.

Unos días más tarde el estamento nobiliar hacía patente que las considerables dificultades con las que el reino se encontraba para hacer frente al servicio concedido en 1626 imposibilitaban la concesión de uno nuevo, al tiempo que solicitaba del rey armas con las que dicho reino pudiese aprestarse a la defensa de sus fronteras ${ }^{34}$. El estamento de caballeros e hijosdaldo, por su parte, abundando en la situación por la que atravesaba el mencionado reino, ponía la defensa del mismo en manos de la corona y, en su caso, pedía las armas, municiones y órdenes necesarias para acudir en su defensa ${ }^{35}$. El estamento eclesiástico fundamentaba su negativa sobre todo en motivos de índole económica, al recordar el calamitoso estado en que se hallaba Aragón, sujeto además al subsidio votado en las cortes de $1626^{36}$. Unos días después, el estamento de las universidades manifestaba también su opinión desfavorable a la concesión del servicio, como en los casos anteriores, basándose en el grado de postración económica en el que se encontraban los aragoneses ${ }^{37}$.

Así estaban las cosas, cuando a finales del verano el virrey, tras recibir a los comisionados que le presentaban los documentos donde se reflejaban las respuestas de los distintos estamentos, les comunicaba que tenía «orden de no resolver nada sin avisar a su Magestad y que lo haría con la maior brevedad posible y en teniendo respuesta la daría ${ }^{38}$. Pero ese encuentro ya no tendría efecto. El 21 de septiembre las Juntas quedaban suspendidas ${ }^{39}$. Pocos días antes, en tierras bávaras, el ejército imperial gobernado por el cardenal infante don Fernando de Austria había vencido a los suecos en Nördlingen, preludiando así importantes acontecimientos, que no tardarían en producirse. Efectivamente, en medio de un ambiente de encendidas diferencias, el 19 de mayo de 1635 el cardenal Richelieu declaraba la guerra a España. Una circunstancia que, a pesar lo acontecido en las últimas Juntas, iba a suponer para Aragón una intensificación del reclutamiento de hombres de armas mediante el «sistema de comisión o procedimiento administrativo» (Solano, 1987, pp. 68-69).

33 BNE, Sección de manuscritos, ms. 6748, doc. 2 (Impreso) ff. 3-5, «Propuesta que el Excelentísimo señor don Fernando de Borja, Comendador Mayor de Montesa, Gentilhombre de la Cámara de su Majestad, y su Lugarteniente y Capitán General de Aragón ha hecho a los quatro Braços dél en nombre de su Majestad, en 20 de agosto 1634». Véase también BRAH, 9/5703 D-93, doc. 25; así como BNE, ms. 6787, Juan José Porter y Casanate, Anales..., ff. 24v-29v. BNE, Sección manuscritos, ms. 6748, doc. 3, «Actas de la Juntas reunidas en la ciudad de Zaragoza» (Registro de su desarrollo hecho por el estamento de Caballeros e Hijosdalgo), ff. 15v-16v y 46. BNE, Sección manuscritos, ms. 6748, doc. 3, «Actas de las Juntas...», ff. 20-21v. BNE, Sección manuscritos, ms. 6748, doc. 3, «Actas de las Juntas...», ff. $23 \mathrm{v}-25$. BNE, Sección manuscritos, ms. 6748, doc. 3, "Actas de las Juntas...», ff. 26v -29. BNE, Sección manuscritos, ms. 6748, doc. 3, «Actas de las Juntas...», ff. 30v-34v. BNE, Sección manuscritos, ms. 6748, doc. 3, «Actas de las Juntas...», f. 40v. 
Así, por ejemplo, en junio de 1636, don Antonio Ximénez de Urrea, V conde de Aranda, recibía la encomienda regia de realizar una leva de 400 hombres de armas, por lo que la diputación del reino concedía licencia al alférez de este, Pedro de Urrea, para que, con el fin de atenderla, pudiese «arbolar bandera y tocar cajas y alistar gente» para levantar una compañía en Zaragoza. Algo que también comunicaba el alférez a los jurados de la ciudad para su aprobación, informándoles que lo hacía por mandato real $^{40}$. Otro ejemplo significativo podemos encontrarlo en diciembre de 1637 , cuando se presentaba Baltasar Núñez de Morales, capitán nombrado por el rey, ante los jurados de la ciudad de Zaragoza para pedir permiso y facultad de levantar gente de guerra. En esta ocasión, se especificaba en su registro de presentación de título de capitán y facultad de enarbolar bandera que era «capitán nombrado por su Magestad del tercio de Don Justo Pérez de Pomar Torres de Mendoza, Maesse de Campo del tercio del presente Reyno ${ }^{41}$. Lo que nos pone sobre la pista del intento de la corona de movilizar un tercio en tierras aragonesas. Tanto los movimientos de las tropas de Valparaíso por las tierras de la Aquitania francesa en 1636, como el contraataque francés del año siguiente y la presión francesa en el Pirineo, son motivos que pueden justificar esta pretensión.

Algo parecido estaba ocurriendo en el reino de Valencia, donde, sobre todo tras la declaración de la guerra con Francia en 1635, los valencianos iban a responder de manera creciente a los requerimientos de índole militar de la monarquía fuera de las cortes (Vilá, 1980, pp. 128-142). El profesor James Casey afirma que «si en la mayoría de los asuntos se dejaba al reino que se gobernara según sus propios mecanismos, en el terreno de la defensa se le exigió desempeñara un papel muy activo en apoyo a la monarquía» (Casey, 1983, p. 230). Mientras tanto, en tierras del Principado de Cataluña, donde continuaba vigente el principio foral de autodefensa, se trataba de mantener el carácter tradicional de su organización militar, optando por soportar el coste de la guerra cuando esta estaba instalada en su territorio (Vidal, 1986, pp. 115116; Simón y Espino, 1993, pp. 143-150).

De nuevo en Aragón el momento más determinante lo encontramos, sin duda, en la petición hecha al reino por los consejos de Estado y Guerra en 1638 para levantar una milicia de apoyo al sitio puesto por los franceses a la plaza de Fuenterrabía. Una solicitud que llegaría a movilizar cerca de 1.000 hombres de los dispuestos por el municipio zaragozano y los ofrecidos por la diputación del reino, a los que se agregaron otros de algunas localidades (Armillas, 1979, pp. 169-188; Solano, 1989, pp. 7-22).

Apenas un año después se reiteraba una nueva petición para que los aragoneses interviniesen militarmente en la defensa del Rosellón, la cual se concretaba en

$40 \quad$ ADZ, Actos comunes, ms. 424, ff. 15v-16v.

41 AMZ, Actos comunes, ms. 57, f. 18. 
la movilización de un tercio bajo el mando de don Fadrique Palafox ${ }^{42}$. Este, como el anterior, quedaba sujeto a las disposiciones forales, lo que limitó su efectividad en medio de lo que ya era una atmósfera de persistentes intentos por parte de la monarquía de definir una estructura de milicias en los territorios de la antigua corona aragonesa, al objeto de hacer frente a las contingencias bélicas. Así ocurrió cuando el rey, aduciendo la escasez de los efectivos militares existentes en Flandes e Italia, en noviembre de 1639 solicitaba a sus virreyes en los respectivos territorios aragoneses que hiciesen las diligencias pertinentes para que, en ellos, por cada cien vecinos, se levantase un soldado, «pues no se podrá juntar gente con menos inconveniente ni más fácil disposición». De esta medida no podría eximirse ninguna localidad que tuviese al menos cincuenta vecinos, debiendo estar la gente alistada en los primeros días de enero de $1640^{43}$.

Muy poco tiempo después, ante el estado en que se encontraban las cosas en el ámbito internacional y las gestiones de la cancillería francesa, en relación con los sucesos que estaban acaeciendo en Cataluña, la monarquía concedía un protagonismo determinante al territorio aragonés (Sanabre, 1956, pp. 91-94). Al esfuerzo contributivo que Aragón estaba realizando era preciso sumar ahora su colaboración con la mencionada monarquía y disuadirlo de cualquier afección con los intereses de los rebeldes catalanes. La corona llegó incluso a considerar la oportunidad de reunir cortes con aragoneses y valencianos, con intención de hacer lo propio con los catalanes algo más tarde. Pero tampoco llegarían estas a realizarse debido a los recelos y a las continuas reticencias de la corte, respondidas desde Aragón con la petición al monarca del cumplimiento de lo estipulado en materia de defensa en las cortes de 1626; una defensa que volvía a recaer, como ya había ocurrido en las cortes de Tarazona de 1592, en manos de la mencionada corona (Solano y Sanz, 2018, pp. 560-563).

Con el inicio de la guerra de Cataluña y ante la urgente necesidad de precaver la defensa de las fronteras del territorio aragonés, la diputación del reino solicitaba del virrey, el duque de Nochera, licencia del monarca para juntar los estamentos, ya que el reino no «podía conforme las leyes y facultad que tiene hazer más» ${ }^{44}$. Una petición que había sido hecha con anterioridad sin que hasta entonces hubiese tenido respuesta. Por fin, el 31 de mayo el virrey autorizaba la reunión de los mencionados estamentos ${ }^{45}$ y el 13 de junio, con la lectura de la «Proposición» ${ }^{46}$, daban comienzo unas Juntas en Zaragoza, que habrían de prolongarse hasta los últimos días del verano, sin que los acuerdos alcanzados en ellas garantizasen los buenos resultados del

42 ADZ, Actos comunes, ms. 399, ff. 65-67, 90v-96, 107v-110.

43 ACA, CA, Secretaría de Aragón, leg.70, «En esta conformidad se ha de hazer despacho para todos los virreyes de la Corona de Aragón incluso Mallorca y Cerdeña», fecha 33-11-1638.

44 ADZ, Actos comunes, ms. 434, ff. 238-239v.

45 ADZ, Actos comunes, ms. 434, ff. 258-259.

46 ACA, CA, Secretaría de Aragón, leg. 72 (Impreso), fecha 13 de junio de 1641. 
servicio comprometido ${ }^{47}$. Así, se había acordado la movilización de 4.800 hombres mediante un repartimiento realizado en los siguientes términos: las ciudades, por cada 8 fuegos tendrían que dar un soldado; las villas y localidades con más de 100 darían uno por cada 11 fuegos; y los concejos de menos de 100 aportarían solo uno por cada 12 fuegos. Estos soldados deberían ser pertrechados y pagados por el rey por un periodo de seis meses, aunque este período sería prorrogable si las circunstancias lo requiriesen, como así fue (Solano, 2006, pp. 179-184).

Corría 1642 cuando tres acontecimientos frustraban las expectativas que Felipe IV había puesto en el escenario bélico catalán. El 10 de junio el mariscal francés La Móthe conquistaba la estratégica plaza de Monzón y su castillo, gobernado por don Martín de Azlor, capitulaba el día 15 de ese mes; la plaza de Perpiñán era tomada por los franceses a mediados de septiembre; y el 7 de octubre el ejército real mandado por el marqués de Leganés, por entonces virrey de Aragón, era derrotado en las proximidades de Lérida por el citado mariscal La Móthe, que ya había sido nombrado por Luis XIII virrey de Cataluña, si bien no había tomado todavía posesión del cargo (Sanabre, 1956, pp. 239-240).

En tan críticas circunstancias, y cuando ya tocaba a su fin el servicio económico ofrecido en las cortes de 1626, Felipe IV, al objeto de prorrogar la movilización acordada en las Juntas de 1641, se dirigía a los aragoneses demandando una nueva contribución militar. Una circunstancia que llevó a los diputados a interponer consulta ante la corte del Justicia de Aragón el 27 de noviembre de $1642^{48}$. La respuesta favorable, sin duda auspiciada por el fuero acordado en 1592 en Tarazona bajo el título «De la facultad de gastar los diputados por consulta», se convertía en justificación de nuevas resoluciones de movilización de milicias, siempre sujetas a fuero, y cuyo ejemplo encontramos en la primavera de 1643 cuando don Agustín de Villanueva Díez, Justicia de Aragón, emitía un bando pidiendo a las localidades del reino que acudiesen en socorro de las tierras de frontera con Cataluña. Entre otras cosas, decía:

Los diputados juntamente conmigo no solo podíamos sino que debíamos convocar la gente que nos pareciere necessaria para este efecto, componerla satisfaciéndoles del sueldo competente, gastando en esto la hazienda que se allase de las generalidades $^{49}$.

47 ACA, CA, Secretaría de Aragón, leg.72, ff. 1-5 «Acuerdo que han tomado los cuatro Brazos del Reino de Aragón, sobre el servicio de gente que hacen a su Magestad»; ff. 6v-16v «Instrumentos públicos y deliberaciones hechas por los quatro Braços del Reyno de Aragón en servicio de su Magestad, entregados a los ilustrísimos señores Diputados del dicho Reyno», fecha 24 de septiembre de 1641 .

48 ADZ, Actos comunes, ms. 443, ff. 114v.-115.

49 ADZ, Cartas misivas y responsivas, ms. 447, ff. 9-10. 
Una afirmación que, más allá de las resoluciones habidas en las Juntas zaragozanas de 1641, representaba la aceptación de las servidumbres que la guerra entrañaba y preludiaba el servicio que se iba a votar en las cortes de Zaragoza de 1646, traducido en una contribución militar de 2.000 soldados pagados por el reino, estructurados en dos tercios fijos de 1.000 hombres cada uno, organizados en diez compañías, «con sus Maeses de Campo, Sargentos mayores, Capitanes y demás Oficiales, Auditor, Veedor, Pagador y Contador, y sus Oficiales». Dicho servicio tendría una duración de cuatro años, si antes no hubiese acabado la guerra en Cataluña, sin que para este efecto se considerasen los condados del Rosellón y la Cerdaña (Sanz, 1997, pp. 99-121).

En las Juntas realizadas en Zaragoza en 1634, los estamentos habían basado su negativa al servicio de armas solicitado por la monarquía argumentando que, vigente el plazo de contribución del Servicio ordinario votado en las cortes de 1626, este les eximía de contribuir con un nuevo esfuerzo. Ahora, sin embargo, superada la vigencia del plazo, con el servicio de armas votado en las cortes de Zaragoza clausuradas en el otoño de 1646, la adecuación de los recursos humanos, materiales y económicos de los aragoneses al aparato de guerra perseguido por la corona durante décadas parecía estar más cerca ${ }^{50}$.

Mientras tanto, la capacidad de acción del virrey y su prestigio político, tras el estallido de la guerra de Cataluña (1640-1652), habían pasado a quedar condicionados por el ejercicio de la capitanía general del ejército del rey instalado en el territorio aragonés, anteponiéndose, de este modo, al tradicional ejercicio de la capitanía general territorial ejercido por el virrey, con quien también llegará a competir la autoridad militar del gobernador, amparada por la corona. Un nuevo escenario en el que, a partir de entonces, tendría que moverse la figura del mencionado virrey (Solano, 2012, pp. 164-167).

\section{Conclusión}

Urgido por la rebelión granadina y consciente de la precariedad defensiva del territorio peninsular, Felipe II había ordenado a su consejo de Guerra que sin dilación estudiase una nueva organización de milicias para implantarla con la mayor celeridad posible, incluso más allá del territorio castellano. Un escenario en el que hay entender la redacción de informes, como el elaborado por Juan López de Velasco en 1571 con

50 Una nueva situación que, como argumenta Xavier Gil Pujol, también puede ser interpretada considerando los cambios experimentados en la propia sociedad aragonesa, sobre todo en el modo de entender la vida pública por parte de su clase política, con el consiguiente cambio de comportamientos y prioridades. Véase Gil, 1988, cuya información ha sido amablemente suministrada por el autor. 
el título «Razones por las cuales el reino de Aragón debe contribuir como los demás reinos a la defensa de España», o el que se remitía a la corte en 1577 desde Aragón, que informaba sobre el estado en que se encontraba la investigación que en el reino se estaba realizando con el fin de organizar la milicia. Un ambicioso proyecto que, aunque finalmente no prosperó, evidenciaba el interés de la corona por contar con un dispositivo militar y de defensa en un territorio de indudable valor estratégico y donde, por entonces, la conflictividad política y social existente, unida al incremento de las acciones del bandolerismo, se había convertido en asunto de creciente preocupación para la corte.

Va a ser en este ámbito, precisamente, donde los esfuerzos de las autoridades aragonesas por hacer frente a esta situación se conviertan en los primeros instrumentos, sujetos a normativa foral con los que la corona va a aproximar la escasa capacidad del dispositivo de defensa en Aragón a su propia administración de guerra. Un contexto en el que también hay situar la creación de la Guarda por parte de la diputación del reino, única estructura militar de carácter permanente, con una función eminentemente policial y dotada de cierto presupuesto económico, la cual, creada en 1569, adquiriría una estructura más definitiva en 1572, después de la operación militar contra el bandolerismo orquestada por la diputación del reino.

Algunos años más tarde, la intervención de la monarquía en los asuntos de Francia y el incremento de la tensión política entre esta y el reino aragonés, se traducirían en un significativo avance de la corona en el control del dispositivo defensivo en Aragón. Efectivamente, en las cortes Tarazona de 1592 se resolvían acuerdos determinantes, referidos a cualquier tipo de prevención armada que tratara de realizarse en el reino. Unas medidas acompañadas muy pronto por el dispositivo de torres y fortalezas para la defensa del Pirineo aragonés propuesto por Tiburcio Spanoqui, y ordenado por Felipe II en 1594. Una decisión que, por otra parte, no hacía sino avivar la conflictividad jurisdiccional ya existente en el Pirineo, motivada por la diferente interpretación dada por el reino y los representantes reales a la aplicación del fuero del «Capitán de guerra». Todo lo cual no hace otra cosa que evidenciar el papel que la corona pretendía asignar al territorio aragonés en la organización defensiva del frente nororiental peninsular.

Así se puso de manifiesto en las Juntas de Zaragoza de 1601, en las que Felipe III pedía a los aragoneses un ambicioso servicio de armas que, por los términos en los que estaba expuesta la solicitud real, y si bien no llegó a comprometerse, preludiaba ya el plan que Olivares habría de presentar veinticuatro años más tarde a Felipe IV con el título de la «Unión de armas».

En respuesta a dicho plan, en las cortes convocadas en Barbastro y clausuradas en Calatayud en 1626, los aragoneses votaban una elevada contribución anual de 144.000 libras jaquesas por un periodo de 15 años en lugar de los 2.000 hom- 
bres de armas que, también, se había barajado conceder; en todo caso, un número sensiblemente inferior al pretendido inicialmente por Olivares en su proyecto. Pocos años más tarde, los estamentos del reino en las Juntas de Zaragoza celebradas en 1634 excusaban movilizar 2.000 hombres de armas a su costa ante la necesidad de prevenir las fronteras del reino. Esto no impediría que luego, con la declaración de guerra entre las monarquías, francesa y española, se intensificase la recluta de hombres en Aragón mediante el «sistema de comisión», aunque los servicios concedidos fuera de cortes, sujetos a normativa foral, continuaran siendo los que adquiriesen un mayor relieve.

Pero fue la guerra de Cataluña (1640-1652) la que representó para Aragón el momento de máxima intensidad contributiva de toda la centuria. En las Juntas de Zaragoza celebradas durante el verano de 1641 se resolvía la movilización de una leva de 4.800 hombres para la defensa del territorio aragonés en servicio de su majestad, estableciéndose para su realización un repartimiento sobre los municipios, que seguía criterios de proporcionalidad. Una novedad que, sin duda, hay que interpretar como un instrumento organizativo de las milicias en el reino. Poco después, la respuesta del Justicia de Aragón a las renovadas demandas de contribución militar recibidas por el rey, se convertía en un claro precedente del servicio de armas que iba a acordarse en las cortes de Zaragoza de 1646.

Habían pasado algo más de ochenta años desde que Felipe II hiciese patente su intención de que Aragón aproximara sus recursos humanos, económicos y materiales a la necesaria renovación que el aparato militar de la monarquía en territorio peninsular requería. Con el servicio de armas votado en la ciudad del Ebro el año 1646, las características del mismo apenas habían iniciado su proceso de transformación, pero su incorporación al aparato de defensa de la monarquía parecía ser un hecho.

\section{AGRADECIMIENTOS}

El siguiente trabajo se enmarca en las actividades del Grupo de Investigación de Referencia H01-20R «Blancas», financiado por el Gobierno de Aragón. La edición de este trabajo ha sido posible gracias a la ayuda del Programa de Grupos de Potencial Crecemento concedida por la Consellería de Cultura, Educación e Universidade da Xunta de Galicia al GI-1921 de la USC (Referencia: GPC, ED 431B 2021/06). 


\section{Bibliografía}

Armillas Vicente, J. Antonio (1979), «Levas zaragozanas para la Unión de Armas de 1638», Estudios 1978, Zaragoza, Departamento de $\mathrm{H}^{\mathrm{a}}$ Moderna, Facultad de Filosofía y Letras, pp. 169-188.

BardaXi y Almenara, Juan (1592), Comentarii in quattuor Aragonensium fororum libros, Zaragoza, Impreso por Laurentium Robles.

CAmón Aznar, José (1959), «La situación militar en Aragón en el siglo XVII», Cuadernos de Historia Jerónimo Zurita, 8-9, pp. 71-143.

Colás Latorre, Gregorio y Salas Ausens, J. Antonio (1975) «Las Cortes aragonesas en 1626: voto del servicio y su pago», Estudios, Zaragoza, Departamento de $\mathrm{H}^{\mathrm{a}}$ Moderna, Facultad de Filosofía y Letras, pp. 87-139.

Colás Latorre, Gregorio y Salas Ausens, J. Antonio (1982). Aragón en el siglo XVI. Alteraciones sociales y conflictos políticos, Zaragoza, Departamento de $\mathrm{H}^{\mathrm{a}}$ Moderna, Universidad de Zaragoza.

Domínguez Ortiz, Antonio (1960), Política y Hacienda de Felipe IV, Madrid, Editorial de Derecho Financiero.

ElLiott, John H. (1977), La rebelión de los catalanes. Un estudio sobre la decadencia de España (1598-1640), Madrid, Siglo XXI.

GASCón PÉrez, Jesús (2004), «La jornada de los bearneses, epílogo de la resistencia aragonesa contra Felipe II», Bulletin Hispanique, vol. 106 (2), pp. 471-496. $<$ https://doi.org/10.3406/hispa.2004.5199>.

Gascón PÉrez, Jesús (2007), Aragón en la Monarquía de Felipe II: Historia, pensamiento y oposición política, Zaragoza, Rolde de Estudios Aragoneses, 2 vols.

GASCón PÉrez, Jesús (2010), Alzar banderas contra su rey: la rebelión aragonesa de 1591 contra Felipe II, Zaragoza, Prensas Universitarias de la Universidad de Zaragoza.

Gil Pujol, Javier (1988), De las Alteraciones a la estabilidad. Corona, fueros y política en el reino de Aragón, 1588-1648, Universidad de Barcelona [Tesis Doctoral inédita].

Gómez de Valenzuela, Manuel (1992), «La invasión del valle de Tena en 1592», Jornadas de Estudio sobre la invasión de Aragón, Cuadernos de Estudios Borjanos, 27-28, pp. 5-64.

GonZÁlez AnTón, Luis (1986), «La Monarquía y el reino de Aragón en el siglo XVI. Consideraciones en torno al pleito del virrey extranjero», Príncipe de Viana, Anejo 2-3, homenaje a José Ma Lacarra, pp. 251-268. 
Gracia Rivas, Manuel (1992), La invasión de Aragón en 1591. Una solución militar a las alteraciones del Reino, Zaragoza, Gobierno de Aragón, Departamento de Cultura y Educación.

JARQUE MARTínEZ, Encarna (1982), «Dos ejemplos de movilización ciudadana en el municipio de Zaragoza (1570 y 1588)», en I Congreso de Historia Militar, Zaragoza, tomo 2, pp. 261-272.

JARque Martínez, Encarna (1991), Juan de Lanuza. Justicia de Aragón, Zaragoza, Diputación General de Aragón, Departamento de Cultura y Educación.

JARque Martínez, Encarna (2007), Zaragoza en la Monarquía de los Austrias. La política de los ciudadanos honrados (1540-1650), Zaragoza, Institución «Fernando el Católico».

Lalinde Abadía, Jesús (1963), La Gobernación General en la Corona de Aragón, Zaragoza, Institución «Fernando el Católico».

Lario Ramírez, Dámaso de (1986), Comte-Duc d'Olivares i el regne de València, Valencia, Eliseu Climent.

Martínez Ruiz, Enrique y Pi Corrales, Magdalena de Pazzis (2012), Las Guardas de Castilla: el primer ejército permanente español, Madrid, Silex,

MúÑoz CASAYús, Pedro-Antonio (1927), «Las Hermandades de Aragón» y «Los capítulos de la Santa Hermandad en Aragón», Universidad, revista de cultura y vida universitaria, 3, pp. 669-723, y 4, pp. 905-959.

Osset Moreno, Enrique (1992), El castillo de San Pedro de Jaca, Zaragoza, IberCaja Obra Cultural.

Rivero Rodríguez, Manuel (2017), El conde duque de Olivares. La búsqueda de la privanza perfecta, Madrid, Ediciones Polifemo. <https://doi.org/10.23854/ autoc.v5i1.196>.

Salas Ausens, José Antonio y Jarque Martínez, Encarna (2003), «Los lugartenientes del Justicia de Aragón», en Fernández Clemente, Eloy (coord.), Cuarto encuentro de estudios sobre el Justicia de Aragón, Zaragoza, Ediciones «El Justicia de Aragón», pp. 155-172.

SANABre, José, (1956), La acción de Francia en Cataluña en la pugna por la hegemonía de Europa (1640-1659), Barcelona, Librería J. Sala Badal.

SÁnchez Molledo, José Ma (1993), «Organización militar en el reino de Aragón durante el siglo XVI», en Actas de las II Jornadas Nacionales de Historia Militar, Málaga, pp. 49-56.

SÁnchez Molledo, José Ma (1996), «Poder real y organización militar en el reino de Aragón durante el siglo XVI», en Falcón Pérez, $\mathrm{M}^{\mathrm{a}}$ Isabel (coord.), Actas del 
XV Congreso Internacional de la Corona de Aragón, Zaragoza, Gobierno de Aragón, Departamento de Educación, Cultura y Deporte, tomo 1, vol. 2, pp. 475-484.

Sanz Camañes, Porfirio (2000), «Las ciudades al servicio del rey. La defensa del Pirineo aragonés ante la invasión del valle de Tena en 1592» en Martínez Ruiz, Enrique (coord.), Madrid y las ciudades de la Monarquía. Las ciudades y el dinero, Madrid, Actas Editorial, tomo 1, pp. 143-156.

Sanz Camañes, Porfirio (1997), Política, hacienda y milicia en el Aragón de los últimos Austrias entre 1640 y 1680, Zaragoza, Institución «Fernando el Católico».

Savall y Dronda, Pascual y Penén y Debesa, Santiago (1866), Fueros, observancias y Actos de Corte del Reyno de Aragón, Zaragoza, Imprenta Francisco Castro y Bosque.

SimÓn i TARRÉs, Antoni y Espino López, Antonio (1993), «Les institucions i formes d'organització militar catalanes abans de la guerra dels Segadors», en Actes Tercer Congrés d'Història de Catalunya, Revista Pedralbes, 13-1, pp. 143-150.

Solano Camón, Enrique (1987), Poder monárquico y Estado pactista (1626-1652). Los aragoneses ante la Unión de Armas, Zaragoza, Institución «Fernando el Católico»,

Solano Camón, Enrique (1996), «Aspectos en torno a la jurisdicción militar en la España de los Austrias», en Martínez Ruiz, Enrique y Pi Corrales, Magdalena de Pazzis (coords.), Instituciones de la España Moderna. Las Jurisdicciones, Madrid, Actas Editorial, pp. 263-292.

Solano Camón, Enrique (2004), «Aragón en la Administración de guerra de la monarquía española durante el siglo XVI», Revista de Historia Moderna, Anales de la Universidad de Alicante, 22, pp. 101-142. <https://doi.org/10.14198/ RHM2004.22.04>.

Solano Camón, Enrique (1996), «El fuero del Capitán de Guerra. Un conflicto de jurisdicción entre Aragón y la Corona», en Falcón Pérez, $\mathrm{M}^{\mathrm{a}}$ Isabel (coord.), Actas del XV Congreso Internacional de la Corona de Aragón, Zaragoza, Gobierno de Aragón, Departamento de Educación, Cultura y Deporte, t. 1, vol. 2, pp. 487-495.

Solano Camón, Enrique (1989), «La contribución armada de la Corona de Aragón ante el sitio de Fuenterrabía», Cuadernos de Historia Jerónimo Zurita, 59-60, pp. 7-22.

Solano Camón, Enrique (2006), «Formas de reclutamiento en la movilización de Aragón durante la guerra dels Segadors (1640-1652)», Obradoiro de Historia Moderna, 15, pp. 173-204. <https://doi.org/10.15304/ohm.15.550>. 
Solano Camón, Enrique y Sanz Camañes, Porfirio (2018), «Política, fueros y conflictos en el Aragón de Felipe IV», en Martínez Millán, José, González Cuerva, Rubén y Rivero Rodríguez, Manuel (dirs.), La Corte de Felipe IV (1621-1665). Reconfiguración de la Monarquía católica. Las Cortes virreinales peninsulares y Flandes, Madrid, Ediciones Polifemo, tomo 4, vol. 2, pp. 543-598.

Solano Camón, Enrique y Sanz Camañes, Porfirio (1998), «La contribución de Aragón en las empresas militares al servicio de los Austrias», Studia Histórica. Historia Moderna, 18, pp. 237-264.

Solano CAmón, Enrique (2012), «La institución virreinal en Aragón durante la Edad Moderna», en Cardim, Pedro y Palos, Joan Luis (eds.), El mundo de los virreyes en las monarquías de España y Portugal, Madrid, Iberoamericana Vervuert, pp. 149-172. <https://doi.org/10.31819/9783954870028-005>.

Thompson, Irving A. A. (1981), Guerra y decadencia. Gobierno y administración en la España de los Austrias, 1560-1620, Barcelona, Crítica.

UlloA, Modesto (1963), «La evolución de la situación de la Hacienda a partir de 1559», en Hacienda Real de castilla en el reinado de Felipe II, Roma, Librería Sforzini.

VILÁ LóPEZ, Carmen Margarita (1980), «La aportación valenciana a la guerra con Francia (1635-1640)», Estudis. Revista de historia moderna, 8, pp. 125-142.

VIDAL Pla, Jordi (1986), «Formes tradicionals de l'organizació armada de Catalunya dels s. XVI i XVII: Suggerències per a una investigació», Manuscrits. Revista d'Història Moderna, 3, pp. 105-116. 